\title{
Luis Unceta Gómez, La petición verbal en latín. Estudio léxico, semántico y pragmá- tico, Madrid, Ediciones Clásicas-Ediciones UAM, 2009, 242 pp.
}

Describir el funcionamiento de una lengua es siempre difícil. La atención a un pequeño sector del sistema, gracias a la ingente labor desarrollada por la lingüística en el siglo XX, se amplía necesariamente en todas direcciones. Con mucha más razón, cuando se atiende a un núcleo de relaciones abstractas definidas por este grupo de verbos latinos. El objetivo al que se orientaba el estudioso de la lengua hace años en la descripción "desde dentro" de la lengua se ha ido ampliando. La teoría de los actos de habla ha mostrado el recurso de la lengua con que se adapta al contexto situacional y al uso adecuado en la comunicación. Ambas perspectivas se complementan. La perspectiva situacional se combina con la interna, en la que las palabras se distinguen por diferencias mínimas que se marcan en la forma y en la semántica.

De ahí que se comience el estudio en dirección opuesta a aquella en que progresa el título. En efecto, detrás de la explicación de los actos de habla en la petición y su trascendencia en la dimensión pragmática del uso de la lengua latina, llega al final la descripción del léxico. El acierto de esta aproximación a la forma de expresión latina se observa también en el tratamiento de distinciones que pueden ser problemáticas si se pretende delimitar el campo de estudio. El esquema básico de la comunicación que se expresa se compone de un emisor y uno o varios receptores que pueden tener entre ellos una diferencia social codificada en la distinción del léxico, de las construcciones sintácticas y de la entonación. Pero además el autor da comienzo a su exposición desde una posición aún más abstracta como es la volición y la intención comunicativa. Por eso la petición se enmarca en las funciones del lenguaje desiderativa e instrumental.

Desde la voluntad humana de condicionar la actuación de otros, la petición se relaciona con construcciones y vocabulario expresivos del mandato y de la inducción del encadenamiento controlado de las causas de un proceso o cambio. En este nivel tan general, el autor recoge de manera crítica y ajustada a su asunto las contribuciones eruditas más señaladas para definir los actos de habla directivos, así como el establecimiento de una cortesía que se materializa en la acuñación de ciertas características de lengua. Esta cortesía está en un plano diferente de la relación cuando el emisor se expresa y tiene un grado determinado de control sobre la realización efectiva de lo que ha manifestado, pero puede combinarse con la incertidumbre sobre la eficacia de la forma lingüística elegida.

De ahí la necesaria distinción de la modalidad de la lengua, deóntica, desiderativa o bien imperativa, que se articula con las variantes indicadas antes y la "combinación y mutua interferencia entre pregunta, consejo, orden o deseo" (p. 39). La distinción clara entre ellas se puede conseguir mediante un léxico especializado e inequívoco, pero la riqueza de matices que impone la convivencia se sirve a menudo 
de la indefinición para mitigar las susceptibilidades. Por eso la lengua debe ser capaz de permitir una cierta gradación de matices que se pueden difuminar todavía más en ciertas situaciones comunicativas. En consecuencia, quien ha asumido el objetivo de describir todo esto debe reparar en todas las que son significativas y pertinentes a la variedad real que el latín ofrece.

En ese aspecto, el presenteestudio no se pierdeenjustificar las posibles situaciones de uso, sino que se atiene a los medios concretos que la lengua latina ha desarrollado, tanto en el plano gramatical como en el léxico, partiendo de una relevancia semántica en esas estructuras. Se compara entonces la forma de los enunciados imperativos en latín, su caracterización del control y del agente, el empleo de los modos del paradigma morfosintáctico con la directividad en el plano léxico. Queda patente la imposibilidad de una caracterización unívoca de las formas de un mismo paradigma de acuerdo con estas funciones del lenguaje.

Algunas formas se prestan mejor que otras a la expresión de las notas semánticas que atañen a los modos del enunciado. La regularidad de los paradigmas aglutina y relaciona usos funcionalmente distintos. Por eso tampoco es de extrañar que el léxico desiderativo pueda tener usos directivos o al contrario. Aún más flexible ha de ser la estructura interrogativa, por tener menor caracterización formal exclusiva, y por eso se aplica también a prestar su indeterminación en esa escala gradual de matices que mencionábamos antes. Y no podían faltar los enunciados declarativos, en sí mismo no caracterizados formalmente para estas funciones, pero que se pueden emplear en contextos bien determinados.

En cambio, al descender al plano concreto del léxico, resulta más evidente la distinción de la modalidad deóntica respecto de las palabras especializadas en las otras modalidades. El lenguaje de la comedia antigua latina permite distinguir los usos pragmáticos en virtud de la caracterización de las unidades textuales cargadas de semántica, los personajes y las escenas. En el texto es posible determinar el rendimiento estilístico de las estructuras implicadas en la petición. Sin embargo, el autor no se detiene en esas realizaciones particulares porque prefiere destacar los rasgos definitorios de cada plano. Por tanto, en el léxico importa más describir la especialización de las distintas unidades en usos sintagmáticos concretos o en el enunciado de valor predominantemente peticionario. Con todo, a pesar de tal especialización de algunos de ellos, "todos los integrantes del campo léxico de la petición pueden funcionar en posición parentética para concretar la intencionalidad de un determinado mensaje" (p. 75). Se confirma así que la petición se combina con una gran variedad de mensajes al definir sobre todo relaciones muy generales entre emisor y receptores. El mensaje puede centrarse en estas exclusivamente o añadir informaciones detalladas a esa relación, en cuyo caso la petición parentética les propone un marco, y el interés se focaliza en el resto del enunciado.

Pero la interpretación de la petición desde la estructura interna del léxico implica detallar esta relación en un proceso en el que se encuentran otros campos semánticos. La recepción y la donación resultan entonces procesos ligados a la petición, así como la 
expresión alterna que frustra la recepción y la promesa preparatoria de las anteriores. Cuando se niega la petición se articulan otros procesos, e incluso se apela a uno de los conceptos que cohesionaban las relaciones comerciales y de convivencia en Roma: la fides, cuyo nombre participa de expresiones complejas con los verbos de petición.

Ahora bien, la estructura del léxico sirve a mismo tiempo a las funciones semánticas fundamentales a las que nos hemos referido, por lo que un aviso de ellas es muy pertinente cuando se trata de la configuración interna de este núcleo léxico (pp. 106-114). Esta justificación metodológica resulta muy oportuna porque los lexemas son abundantes, frecuentes en su uso pero sus rasgos aparecen dispersos en el desarrollo del campo al servir a relaciones tan abstractas. Tal dispersión se comprende además como una adaptación histórica a medida que la sociedad romana adquiría complejidad, por lo que se consigue con procedimientos de desarrollo léxico que progresan hasta la consolidación de la lengua literaria, como la modificación con proverbios y sufijos.

La estructura que definen las relaciones fundamentales del campo se articula según el grado de coactividad determinado fuera de la lengua, la eficacia rogativa y la intensidad de la petición que sí están discriminadas internamente. De ello se concluye que "lo pragmático, así, adopta materialización léxica en estos verbos y, a la inversa, el léxico recibe el influjo de lo pragmático" (p. 209).

Observemos las aplicaciones de lingüística general al conocimiento de las distintas lenguas indoeuropeas que sugiere este estudio, al tiempo que fundamenta un conocimiento cierto de las condiciones de uso del vocabulario latino. Precisamente a este grupo de interés puede satisfacer el repertorio final en el que se registra la lista de verbos, cada uno con unos rasgos esquemáticos acerca de su posición en el campo semántico, su uso y su representación en la lengua literaria, o en los registros especializados religioso o jurídico. A este respecto se observa la atención que a lo largo de las explicaciones se ha venido prestando a los usos técnicos del vocabulario. Su importancia se entiende en un plano de interpretación construido por la cultura romana con ayuda de la lengua. Emisor y receptores mantienen una comunicación definida por otras muchas reglas que no están en la estructura del latín. Pero esta estructura sugiere la elevación de ciertas unidades a ese plano de uso; por eso no es forzada ni totalmente convencional la especialización y tiene un sustento coherente con la lengua no especializada.

Los temas que se han ido suscitando al hilo que ha ido tendiendo el autor resultan muy sugestivos y seguro que muchos de ellos serán materia de discusión en adelante. Depende de la perspectiva desde la que construyamos nuestra descripción podemos profundizar más en algunos aspectos. Pero creo que el haber unido coherentemente tantas facetas pertinentes a la caracterización de los verbos latinos no desmerece la importancia de esos problemas y proporciona evidencias a un modelo teórico recurrente que es la lengua como sistema. Más aún cuando se describe una lengua antigua y conocida por una variedad limitada de textos. 